\title{
FAUSTINO RIBEIRO JUNIOR: ALIMENTAÇÂO, SAÚDE, DOENÇA E PRÁTICAS CURATIVAS EM SALVADOR NO LIMIAR DO SÈCULO XX
}

FAUSTINO RIBEIRO JUNIOR: NUTRITION, HEALTH, DISEASE AND HEALING PRACTICES IN SALVADOR ON THRESHOLD OF THE XX CENTURY

Rafael Rosa da Rocha*
xrr.rocha@gmail.com

RESUMO: Este artigo analisa o cenário de saúde e doença em Salvador nos idos do começo do século XX, a partir de um curandeiro paulista chamado Faustino Ribeiro Junior. Colocamos em perspectiva a questão alimentar. A princípio argumentamos que a dieta monoalimentar da população da cidade de Salvador impacta diretamente na contração de doenças que compunham, de alguma maneira, o dia a dia das pessoas como o beri-beri, doenças estomacais e outras. Igualmente, discutimos os embates entre Professor Faustino, como ficou conhecido o curandeiro, e a Inspeção de Higiene chefiada pelo renomado médico baiano Antonio Pacífico Pereira. O embate se deu no contexto das reformas urbanas cariocas tendo reflexo direto na mentalidade das elites baianas. Nesse sentido, a tensão foi informada pelas concepções de civilização e progresso, reelaboradas na República, para combater os elementos de atraso da sociedade da época.

PALAVRAS-CHAVE: Faustino Ribeiro Junior, Alimentação, Práticas de cura.

ABSTRACT: This article analyzes the context of health and disease in Salvador in the early twentieth century, from a healer named Faustino Ribeiro Junior from Sao Paulo. We point the food issue. At first argue that little varied diet of the population in Salvador impacts directly in the contraction of diseases that were part of everyday life of people like beri-beri, stomach ache and other diseases. Also discussed the conflicts between Professor Faustino, as it became the healer known, and the Hygiene Inspection headed by renowned Bahian physician Antonio Pacífico Pereira. The clash took place in the context of Rio's urban reforms with a direct impact on the mentality of the Bahian elites. In this sense, the tension was informed by the concepts of civilization and progress, reworked in the Republic, to combat the delay elements of the society of the time.

KEYWORDS: Faustino Ribeiro Junior, Feed, Healing practices.

\footnotetext{
* Mestrado em história social pela Universidade Federal da Bahia. Professor de História no Instituto Federal de Educação, Ciência e Tecnologia Baiano, IFBAIANO, (2015).
} 


\section{Introdução}

Em 1903 aportou na capital baiana um renomado "curandeiro" conhecido em São Paulo, Rio de Janeiro e Minas Gerais por suas "curas maravilhosas". Ao desembarcar em Salvador Faustino Ribeiro Junior causou muito alarde nos periódicos locais e nos órgãos de higiene. Branco e letrado, filho de um juiz de direito de Campinas que curava com a imposição das mãos, Faustino confundiu os sinais para as elites da cidade acostumadas a lidar com a repressão aos candomblés, aos batuques e, de modo geral, as práticas sociais, culturais e religiosas africanizadas.

Ele nasceu no ano de 1870. Formou-se professor pela Escola Normal Superior de São Paulo. Na década de 1890, quando atuava como inspetor escolar, passou a realizar suas curas com a imposição das mãos. Após isso, começou a transitar entre São Paulo e Rio de Janeiro realizando suas curas. Entrou em diversos embates naquelas localidades. Fez-se famoso e usou de seu prestígio para angariar clientes em outros Estados.

No cenário conflituoso, onde as prerrogativas de "civilização" e "progresso" se faziam presentes, é possível perceber através do agente de cura paulista as nuanças dos órgãos de higiene e o estado de insalubridade no qual a cidade estava inserida. Nesse texto analisamos o contexto no qual Faustino Ribeiro Junior atuou em Salvador e a relação entre saúde e doença através do aspecto alimentar. Para tanto, utilizamos periódicos locais de grande circulação como o Diário da Bahia e o Diário de Notícias. Igualmente, abordamos os embates que o curador teve com o Inspetor Geral da Higiene pública e a interpretação que os agentes do órgão fizeram da prática curativa de Faustino. Nesse ínterim, utilizamos como fontes principais para a análise os periódicos Correio do Brasil e Diário de Notícias e o processo criminal impetrado contra Faustino pelos órgãos de saúde.

\section{Alimentação, saúde e doença na Bahia.}

Angelina Ceva da Paz, Bolívia, nasceu delicada e doentia. Na sua infância viu-se atacada de uma anemia profunda que acabou de aniquilá-la. Com frequência se encatarroava [sic] e as febres não a abandonavam. Todos os cuidados maternos eram inúteis, se lhe receitavam remédios e mais remédios e a menina piorava. Em tal estado se suspendeu todo tratamento e por indicações do médico administrou-lhe a Emulsão de Scott Legítima. Desde o primeiro frasco se notou uma mudança favorável. A criança 
começou a adquirir carnes e forças, seu semblante de amarelado se tornou rosado e atualmente a sua saúde é perfeita. (DIÁRIO DA BAHIA, 1904, p. 3.)

No dia 26 de janeiro de 1904, o Diário da Bahia, em sua página de anúncios, trazia um enredo de um caso bastante ilustrativo, aparentemente ficcional, da trajetória doentia de Angelina Ceva, que só teve sucesso quando um médico prescreveu a Emulsão de Scott. A Emulsão, um composto, rico em vitaminas A e D, formado a partir do óleo do fígado de bacalhau era uma fonte de nutrientes difíceis de serem obtidos na dieta pouco variada dos soteropolitanos.

Algumas semanas antes da publicação do anúncio supracitado, o Diário da Bahia veiculou outra propaganda acerca da Emulsão - era comum ver publicações desse tipo nos periódicos da época. Segundo a propaganda, o preparado de óleo de bacalhau "levanta a resistência orgânica, contribui para o aumento das forças físicas, priorizando nervos e músculos, regulariza a digestão e estimula o apetite. Sabor agradável e um aproveitamento fácil." Por fim, não deixava de alertar em letras garrafais a "absoluta eficácia" contra "a anemia, tísica, 'rachitis' [sic], enfermidades nervosas, do peito e pulmões, alterações do sangue, dentições difíceis e crescimento rápido." (DIÁRIO DA BAHIA, 1904, p. 3.)

A carência das vitaminas A e D, presentes na Emulsão de Scott, afetava sobremaneira os tecidos epiteliais de órgãos, mais especificamente dos olhos, e o crescimento do ser humano. Em síntese, a ausência vitaminas causava problemas de ordem física e cognitiva. Nesses termos, a Emulsão se apresentava como um medicamento contra fraquezas e que, de algum modo, servia para "combater" o estado de subnutrição da população soteropolitana. Isso não explica a recorrência de pessoas a curandeiros como Faustino, mas com certeza, figurava entre os problemas que deveriam ser enfrentados pela Inspeção de Higiene. $^{1}$

De acordo com Nikelen Acosta Witter (2007, p. 93-94), naquele contexto, os doentes não pareciam destituídos de poder sobre seus corpos. Sabiam muito bem a quem recorrer em caso de doença. Em contraponto à concepção de paciente que sugere alguém que "foi destituído de todo o poder sobre a sua doença", eles pareciam "ter liberdade em escolher a quem chamar para curá-los e que tipos de tratamentos seguir ou não seguir". Entendemos,

\footnotetext{
${ }^{1}$ Sobre a propaganda de medicamentos em periódicos ver: Liane Maria Bertucci (2003, p. 198.) que analisa, no cenário da gripe espanhola de São Paulo, o linguajar utilizado pelas propagandas dos remédios chamados oficiais, para tentar resgatar as semelhanças e diferenças em relação a fala classificada como de curandeiros e charlatães. O mote do trabalho da autora é demonstrar como o vocabulário "de curandeiros e charlatães" foi apropriado pelos farmacêuticos e preparadores que vendiam seus medicamentos nas páginas de alguns jornais da imprensa operária paulista, "por induzir a crença no mundo maravilhoso de curas espetaculares".
} 
a partir de Witter (2007), que a falta de médicos e a carência nutricional, não impulsionavam os doentes, sofredores², a consultar "feiticeiros" e "curandeiros" como Faustino.

Para Witter (2007), essa é a concepção que se opõe a uma "lógica da falta", na qual práticas de cura de certas épocas eram explicadas a partir da tripla ausência: "médicos, remédios, serviços de saúde". Nesses termos, a autora busca entender as práticas de cura como "elementos componentes de um mesmo leque de possibilidade e ação". E igualmente, mostra que a saúde e a doença são "uma fonte de preocupações cotidiana e não um acaso devido à acidentes particulares ou episódios de cataclismos epidêmicos." Esses eventos: epidemias, falta de médicos, deficiência nutricional, compunham um contexto, mas não determinam a recorrência dos doentes a curandeiros como Faustino.

De acordo com Mario Augusto dos Santos (2001, p. 70), a dieta da população baiana das classes baixas era composta pelo "bacalhau salgado", "feijão dormido", "farinha de mandioca", "carne de sertão assada", "pão de trigo". Alguns artigos não faziam parte da dieta ou se apresentavam de forma esporádica, como o peixe fresco, galinha e ovos, verduras e o arroz. As condições precárias de pesca não permitiam produção do peixe em larga escala. Ele era consumido pela elite e pelas próprias comunidades de pescadores. Galinha e ovos eram reservados a almoços especiais e na dieta dos moribundos. Verduras só entravam na composição do cozido por pessoas de recursos medianos.

As carnes salgadas alternavam no consumo básico, sobretudo dos trabalhadores. Naquele cenário o dado fisiológico era importante: "sendo o charque e o bacalhau de digestão mais lenta do que a carne fresca, proporcionavam sensação de saciedade mais prolongada, principalmente se as carnes salgadas fossem acompanhadas de pirão de farinha." (SANTOS, 2001, p. 70-71.) Contudo, esses alimentos agiam de maneira danosa sobre o sistema digestivo. O charque, por exemplo, "obrigava o estômago a um fatigante trabalho", sendo atribuído a carnes secas e salgadas doenças tais quais dispepsias, gastrites, gastrenterites. (SANTOS, 2001, p. 78.)

De acordo com Massimo Montanari, a sensação de saciedade já havia sido enaltecida nos finais do século XVIII quando a "comida pesada" era consumida e o processo de má digestão reverenciado, segundo a elite da época, pelos camponeses para "afastar - o máximo possível - o frustrado desejo de comer." (MONTANARI, 2003, p. 186.) Entretanto, esses alimentos agiam de maneira danosa sobre o sistema digestivo. O charque, por

\footnotetext{
2 De acordo com Nikelen Witter (2007, p. 98.), dialogando com Roy Porter compreende-se por sofredores “o doente, seus parentes e amigos próximos, enfim todos os que se envolviam e se preocupavam com a dor e o destino do enfermo.”
} 
exemplo, "obrigava o estômago a um fatigante trabalho", sendo atribuído a carnes secas e salgadas doenças tais quais dispepsias, gastrites, gastrenterites. (SANTOS, 2001, p. 78)

Ademais, as comidas salgadas impulsionavam ao consumo constante de água, o que Montanari chamou, na Europa, referindo-se também ao consumo de carnes de conserva, de "sede crônica". Na Bahia, nos anos iniciais da República, a água era consumida, sobretudo, de chafarizes públicos para cozinhar e beber. Eram armazenadas em talhas de barro ou cerâmica para conservar fria. A água consumida assim, sem o devido tratamento, foi o "Calcanhar de Aquiles" das epidemias de cólera de 1855 e 1856. Anos mais tarde, o cólera se tornaria endêmico, assolando a população baiana sazonalmente. Além do cólera, a diarreia infecciosa, também contraída através da água mal tratada, grassava Salvador constantemente. (DAVID, 1996.)

O arroz era prato acessório das classes médias e abastadas. Esse item estava ausente, portanto, da dieta das populações de grupos menos favorecidos. Isso pode justificar a grande presença do beribéri na Bahia dos anos iniciais do século XX. O beribéri era uma doença de natureza carencial, que resultava em perda e fraqueza de massa muscular, fraqueza gastrointestinais e dificuldades respiratórias. Na Bahia, além da escassez do consumo de arroz que, como vimos, era base complementar da dieta das classes médias e altas - sendo raro nos grupos menos favorecidos -, tem como causa uma alimentação monótona de ingestão elevada de carboidratos através da farinha. Acrescente-se às causas do beribéri o consumo de álcool, as diarreias e vômitos por períodos prolongados que causava a desidratação e também a fraqueza dos músculos. (PADILHA, 2011.)

É possível encontrar na produção e consumo de arroz da Europa uma explicação para a grande presença do beribéri na Bahia. Em meados do século XIX, o consumo de grãos integrais diminuiu severamente, o que provocou a redução da ingestão de fibras na dieta e perda do valor nutritivo dos cereais. De acordo com Ariovaldo Franco, nos países onde a alimentação era à base de arroz, o que se comia antes de 1850 era arroz integral, "geralmente polido em casa, para consumo imediato." Nesse momento, com o surgimento da indústria de beneficiamento, muitas pessoas passaram a consumir o arroz branco. Para ele, esta indústria não se limitou a remover a casca do arroz, mas passou a poli-lo, "pois o arroz sem polimento não pode ser armazenado por muito tempo." (FRANCO, 2004, p. 222)

Segundo Ariovaldo Franco (2004, p. 222.), um dos resultados do consumo de arroz polido, "pobre do ponto de vista nutritivo, foi o número alarmante de casos de beribéri." Só em 1910 percebeu-se que o beribéri era causado por carência de tiamina ou vitamina B1 e que comer arroz integral seria a solução do problema. Nesse proceder, sugeriu-se adicionar 
vitamina B ao arroz beneficiado. Essa prática, no entanto, foi mais difundida nos países industrializados, onde o arroz tem menor importância na dieta."

Medicamentos sugerindo a cura do beribéri povoavam as páginas de anúncios dos periódicos baianos como o Diário de Notícias e o Diário da Bahia. A publicidade teve um papel fundamental na normatização do consumo de medicamentos farmacêuticos licenciados pela Inspetoria de Higiene. Era preciso persuadir a população consumidora a adotar novos padrões comportamentais para o consumo de medicamentos em detrimento das práticas de tradições enraizadas na cultura soteropolitana, bem como a reduzir a concorrência com curandeiros com os da guisa de Faustino Ribeiro Junior. Segundo Ariovaldo Franco, a publicidade buscava maior simpatia do consumidor. Nesse sentido, "os consumidores eram aconselhados a recusar as imitações e a exigir o produto verdadeiro'." (FRANCO, 2004, p. 221.)

Liane Maria Bertucci (2003, p. 204.), analisando o cenário da gripe espanhola em 1918, em São Paulo, dá sugestivas pistas para compreendermos a lógica dos anúncios de remédios nos periódicos. Segundo a autora, no "universo estabelecido pela presença da influenza, os remédios muitas vezes eram apregoados como possuidores de mais de uma das virtudes necessárias para o combate à moléstia". Além disso, Bertucci (2003, p. 208.) argumenta que as propagandas exploravam "desde o medo das pessoas em contrair a doença até a alegria daqueles que haviam se livrado da terrível moléstia, produtos e serviços aproveitavam a desgraça representada pela gripe espanhola para tentar ganhar dinheiro." É possível que mesmo quase quinze anos antes da gripe espanhola, nos idos de 1903, quando Faustino passou pela Bahia, que essa tenha sido a lógica de funcionamento dos anúncios dos periódicos de Salvador, em relação ao cenário nutricional da sociedade.

O Elixir e Linimento anti-beribericos, anunciado como "A cura do beri-beri no foco", propagou que "qualquer que seja a forma ou gravidade do beribéri, não reaparecendo mais, sem as tormentosas mudanças e os incontáveis banhos salgados". Como vimos, o beribéri se desenvolvia devido a carência de vitamina $B$ e tinha como consequência a fraqueza muscular e problemas intestinais. Entretanto, o anúncio deixa a ver que o Elixir era um experimento baseado em tentativas e erros, visto que, possivelmente, desconheciam a natureza do transtorno, materializando-se como uma alternativa aos banhos salgados. Para reafirmar e dar legitimidade ao medicamento o anunciante veicula sua marca aos "distintos" médicos dos hospitais e enfermarias militares. (DIÁRIO DE NOTÍCIAS, 1903, p. 2.)

Havia entre os hospitais aqueles que funcionavam de maneira temporária em momentos de crise, como o Mont Serrat e os regulares em seu funcionamento. Segundo Custódio Moreira Souza Junior (1886, p. 62 apud SOUZA, 2009.), dentre eles estavam o 
Hospital da Santa Casa de Misericórdia, o Hospital Militar e o Hospital Português. Tais hospitais eram vistos com desconfiança pela população, e com desgosto por parte dos médicos que ali trabalhavam. Para a autora, o povo pobre acreditava que esses espaços eram "antes de morte do que de cura" e os "médicos criticavam as péssimas condições de higiene do ambiente e da alimentação hospitalar, as quais predispunham os enfermos a outras doenças, acelerando a sua morte."

Convivendo lado a lado com essa realidade, compondo um mesmo leque de possibilidades de ação, estava a cura através das crenças e tradições religiosas. A presença de "feiticeiros" e "curandeiros", como Faustino, constituiu-se a partir dos tempos da fisicatura ${ }^{3}$, como um grande encalço para os médicos higienistas do limiar do século XX, que idealizavam a modernidade baseada no modelo europeu e continuavam como uma saída para a maioria da população. A crença religiosa e o medo dos hospitais, pouco eficazes que não dialogavam com a realidade dos que o buscavam, fizeram com que as pessoas continuassem a recorrer a feiticeiros e curandeiros, recorrendo à medicina oficial nos últimos casos.

Atrelada a essa conjuntura, na qual a ciência médica buscava fincar seus pilares saneando os espaços, controlando as habitações e os costumes, ignorando, todavia, o estado constante de subnutrição da população local, a reinvenção das concepções de civilização e progresso davam legitimidade às ações da Inspeção de Higiene. Jorge Carreta (2011, p. 677-700), entretanto, abordando as controvérsias científicas no limiar da República, aponta no cenário da febre amarela e da varíola - concordando com Gabriela Sampaio e Jairo Benchimol -, que mesmo desenvolvendo técnicas bacteriológicas e sorológicas para combater tais enfermidades, havia divergências acerca dos procedimentos adotados para esse fim dentro do próprio grupo médico. Se havia desacordo acerca dos procedimentos dentro do próprio grupo, fora dele o cenário era ainda mais heterogêneo. Nesses termos, não eram poucos os que figuravam em confrontar essa realidade idealizada pelas elites médica e intelectual. Sambas, batuques, carnavais, candomblés, feiticeiros e curadores - tal qual Faustino - circundavam e confrontavam o discurso que se queria impor. (FERREIRA FILHO, 1999.)

\footnotetext{
${ }^{3}$ A fisicatura era o órgão que regulava as práticas médicas no Império - entre 1808 e 1828. Licenças e cartas eram obrigatórias para quem exercesse atividade relacionada às artes de curar. Entretanto, já era possível notar ai uma hierarquia entre as práticas terapêuticas populares e a medicina oficial. Apesar da hierarquização, tornar oficial as práticas de cura populares significava reconhecer aquele saber como legitimo. Isso permitia a inclusão dos terapeutas populares entre aqueles que tinham autorização para exercer atividades de cura. (PIMENTA, 2003.)
} 
Esse era o cenário de Salvador no início do século XX. A cidade estava frente a um constante e quase que perene mal-estar, a um estado de subnutrição que passou a ser usando os termos de Massimo Montanari (2003, p. 164) - "assimilado" fisiologicamente como uma condição normal de vida, mas ignorado pelos órgãos de saúde. Nesse sentido, Montanari (2003, p. 175-176) afirma que "a monotonia do regime alimentar" configura sempre um perigo para a sobrevivência dos indivíduos. Não somente devido uma dieta variada que "é a única que permite um desenvolvimento equilibrado do organismo"; "mas porque a própria garantia de comida, a possibilidade de obtê-la cotidianamente é tanto mais assegurada quanto mais diversificado o leque de recursos disponíveis."

Faustino Ribeiro Junior, e outros tantos feiticeiros e curandeiros, foi um personagem fundamental para pensarmos a situação da sociedade baiana dos anos iniciais do século XX. A carência alimentar endêmica se apresentava, no dia a dia da maior parte das pessoas de Salvador, relacionada a uma crise geral de saúde que figurava ao lado de outros fatores como a insalubridade das habitações, epidemias, endemias, a carestia e a falta de médicos. Esse era o cenário que a Inspeção de Higiene tinha que enfrentar com muito esforço para satisfazer sua ânsia "modernizadora". Muito embora tal realidade não pavimentasse os caminhos para que Professor Faustino tivesse espaço de atuação, o colocava também como um entrave para o "projeto modernizador" das elites da época. Tal condição foi suficiente, dentre outros fatores, para que um embate se instalasse.

\section{Professor Faustino e seu processo de cura, segundo os agentes da Inspeção.}

Faustino entrou em confronto com a Inspeção Municipal de Higiene, dirigida pelo renomado doutor Antônio Pacífico Pereira que se empenhou em combater as práticas de cura do "mago Fausto", pois Faustino Ribeiro "dificultava o trabalho da higiene pública." (DIÁRIO DE NOTÍCIAS, 1903, p. 1.) O que estava em jogo era a legitimidade do saber científico, atrelado a imagem do Antonio Pacífico, mas também um risco ao projeto modernizador $^{4}$ que, mesmo permeando boa parte do século XIX, materializava-se no discurso de inauguração da República.

\footnotetext{
${ }^{4}$ Jorge Carreta (2011, p. 692-693.) aponta que para assegurar seu projeto científico e de alguma maneira modernizador, através do Instituto Manguinhos, Oswaldo Cruz, mesmo diante das controvérsias e incertezas diante da sorologia afirmava seu lugar de destaque na instituição. Sobre essa perspectiva Carreta questiona e responde logo em seguida: Por que Oswaldo Cruz era tão enfático em afirmar a segurança do uso de soros e vacinas, se pairava uma incerteza sobre a segurança desses produtos fornecidos por seus colaboradores do exterior e do Brasil? Por certo, além da crença na validade das técnicas de produção de soros e vacinas, era preciso preservar o projeto de Manguinhos e seus planos para a saúde pública. Cruz devia acreditar que era uma questão de tempo até que os soros estivessem totalmente aperfeiçoados e que pequenos acidentes eram toleráveis
} 
O processo curativo empregado pelo "Fausto" alardeou a Inspeção de Higiene, que logo se pôs a investigar os seus procedimentos de cura. Enviou, portanto, dois ajudantes à residência de Faustino Ribeiro, na Rua Visconde de Itaparica, no centro da cidade, para verificar suas práticas curativas. (DIÁRIO DE NOTÍCIAS, 1903, p. 1.) Quando lá chegaram, encontraram uma multidão de pessoas amontoadas nos corredores e nos vários cômodos que perfaziam a residência onde habitava o curador peregrino. Segundo os relatores de observação,

Não devo nem posso também deixar de consignar a impressão fundamente desagradável que senti com o assistir ao triste espetáculo de dezenas ou mesmo centenas de pessoas aglomeradas tanto nas proximidades como dentro do prédio onde se acha o consultório, quase todas doentes, muitas das quais febricitantes, outras de afecções contagiosas, a maioria exposta durante longo tempo às variações de temperatura diurna, e todas na mais condenável promiscuidade. (DIÁRIO DE NOTÍ́CIAS, 1903, p. 1.)

Para a Inspeção de Higiene o que estava em jogo também era o medo da difusão de "toda a sorte de morbus contagiosos e de germes ocultos de possível necrose epidêmica, bem como de conturbação da ordem." (BRASIL, 1904, p. 10.) A atuação de Faustino foi, nos termos de Pacífico Pereira, um "atentado" ao "decoro público", por Salvador ser uma cidade populosa e pelo fato "de haver se convertido em foco ou centro de agentes infecciosos o prédio onde reside e dá consultas." Ademais, desdenhava dos preceitos sanitários como aplicar, sem a assepsia necessária as mãos "que, postas antes sobre um doente de moléstia contagiosa, são logo depois colocadas sobre doentes de morbos outros, constituindo-se destarte as suas próprias mãos um meio fácil e pronto de veicular germes patogênicos".

É possível reconhecer no discurso de Pacífico uma questão de perigo à saúde pública quando do ajuntamento de pessoas com enfermidades diversas, inclusive contagiosas. ${ }^{5}$ Esse elemento é importante, visto que os lugares de cura - tanto na rua do consultório, quanto no próprio consultório - eram frequentados por centenas de pessoas de várias comunidades que poderiam transmitir tais doenças, se a contraíssem, para dentro das suas próprias

em nome de um bem maior, a erradicação das moléstias epidêmicas. [...] Diante da dificuldade de convencer os pares, muitos recorriam à retórica para sustentar suas descobertas. Assim, mesmo sem poder atestar a segurança dos soros, Oswaldo Cruz empenhava-se em desacreditar seus adversários acusando-os de pouca intimidade com a medicina experimental.

${ }^{5}$ A alimentação carente de nutrientes também poderia ser encarada como uma questão de saúde, mas o que estava em jogo, sobretudo, era a crença e o atraso nos costumes da época. 
comunidades. Entretanto, se por um lado havia uma questão de demanda prática, por outro uma demarcação de lugares sociais era evidente.

Sujeitos como Faustino atormentavam os médicos da época, tanto pela disputa de um mercado que se queria construir, quanto pela concorrência que os doutores e as Faculdades de Medicina viam em pessoas como Faustino Ribeiro Junior. Isso repercutiu de forma acentuada na imprensa baiana. Este discurso continuou vivo e não se furtou em enquadrar Professor Faustino dentro dessa lógica que visava proteger a medicina científica e, portanto, o lugar de fala do relator. Segundo ele,

Uma das histéricas, acompanhada por pessoa de sua família, chegou à presença do afamado professor em plena crise nervosa e, não obstante a imposição das mãos deste sobre o tórax durante vinte minutos, o ataque, após a retirada das mãos, pareceu incrementar-se tomando então a forma convulsiva.

Quanto à outra nevropata [sic], nada digno de menção se ofereceu antes, durante e depois do tratamento, se me afiguro que nenhum influxo benéfico sobre ela fora exercido.

Em relação à terceira, que se apresentou como surda, melhora nenhuma pude observar após a aplicação do especial processo, pois que não respondeu à pergunta que repentinamente lhe fiz sobre o seu estado, apesar de ter sido a 2 2 a ou $3 \underline{a}$ vez em que submetia-se a este curativo. (DIÁRIO DE NOTÍCIAS, 1903, p. 1.)

Os ajudantes de inspetoria, os doutores Ribeiro de Barros e Manoel Gordilho, que foram à residência de Faustino para obterem a prova empírica, de "visu", do procedimento "extraordinário" de "curas milagrosas" empregado pelo "Fausto", narraram em seu relatório com doses de ironia e sarcasmo o processo curativo seguindo desacreditando as práticas de cura e tornando insignificante a crença popular. Um número de enfermos já avultados o procurava. Nas palavras dos doutores,

Para a consecução mais ou menos abreviada desse objetivo, isto é, da cura, importava tão somente tocar ou comprimir com as mãos as regiões ou pontos afetados, ou aqueles onde o paciente acusa mais intenso sofrimento, ignorando entretanto (disse ele) os rudimentos da ciência médica, nomes da moléstia e suas causas gerais, e até noções da terapêutica sugestiva, etc. (DIÁRIO DE NOTíCIAS, 1903, p. 1.) 
Os relatores continuam descrevendo suas impressões enviesadas do processo curativo de Faustino. Chamado à inspetoria para apresentar o título de mestre, o curador declarou, por "escrito" e "verbalmente", que

cura por uma influência que o povo experimenta e afirma, e que ele mesmo ignora supondo em sua crença que se trata de um fenômeno propriamente teosófico, isto é, de uma manifestação de nosso Supremo Pai de infinito amor e misericórdia.

Faustino é, portanto, teósofo, isto é, um iluminado que tem a pretensão de estar em comunicação com a divindade, da qual recebe a faculdade extraordinária que diz possuir.

Analisado, porém, o processo por ele empregado, reduz-se pura e simplesmente a sugestão, que sua completa ignorância do que há de mais rudimentar em medicina, e é conhecido dos espíritos medianamente cultos, não permite distinguir em suas diferentes formas e variadas aplicações. (DIÁRIO DE NOTÍCIAS, 1903, p. 1.)

Muitos foram os adjetivos atribuídos a Faustino: discípulo de Mesmer, teósofo, sugestionador, dentre outros... Entretanto, a cura através das mãos tem uma longa trajetória na história do mundo, como apontamos no início do primeiro capítulo. O processo curativo que ignorava a descrição dos nomes das moléstias e suas causas gerais as quais Faustino dizia ignorar, fugia bastante da perspectiva catalográfica e descritiva de Carlos Lineu (1707-1778) no século XVIII e que orientou, de certa maneira, as frágeis concepções médicas que imperou durante o século XIX e adentrou os primeiros anos do século XX com alguma força. Na realidade, Faustino declarava que não compreendia e nem sabia explicar a natureza da força mística que "dizia" possuir; e costumava "alegar que as suas práticas não pertencem absolutamente ao exercício da medicina", visto que, para alcançar o que objetivava, não lançava mão de "substância medicamentosa nem de hipnotismo, magnetismo ou coisa que os valha." (DIÁRIO DE NOTÍCIAS, 1903, p. 3.) Em outras palavras, fugindo da associação com uma "ciência" meramente supersticiosa pertencentes à maioria das pessoas, leia-se práticas consideras ilegais, de acordo com os médicos da época.

Fugir dessa estrada pouco pavimentada que ocupava a mentalidade das elites médica, jurídica e jornalística baiana, não surtiu tanto efeito para Faustino, vez que, como mostramos no capítulo anterior, sua imagem foi utilizada por alguns periódicos de oposição na composição do jogo político local. Ademais, os periódicos baianos, como os da guisa do 
Correio do Brasil, não deixavam de enfatizar a péssima influência que Faustino exercia sobre a população. O primeiro objetivo do articulista é desconstruir o argumento do curandeiro de que não empregava "nenhuma droga ou produto medicinal de qualquer espécie." Considerando essa prerrogativa uma ilusão, o jornalista levanta uma hipótese para a atuação do "doutor bota-mão".

O indivíduo A tem, suponhamos, uma moléstia de origem sifilítica e da qual uma das manifestações é a dor de cabeça intensa e característica; este indivíduo esta sendo sujeito a uma medicação especial que o porá [sic] bom. Inteiramente bom, no fim de certo prazo, desde que não tenha ele algumas das lesões irreparáveis da infecção uterina. Nesse entretanto, [sic] aparece o apregoado curandeiro, a transformar suas mãos em verdadeira cornucópia de milagres, o doente insulta-o e ele, ignorante das coisas medicas, incapaz de diferenciar uma dor de cabeça comum, nervosa, de outra infecciosa, garante a cura ao pobre, sujeita-o às imposições das suas mãos, enche-os de sugestão, conseguindo de fato melhorar consideravelmente a dor de cabeça de que padecia 0 doente. A cura será proclamada gloriosamente aos quatro ventos, atestados serão passados [...] os medicamentos serão completamente desprezados pelo doente $[\ldots]$

Entretanto, enquanto o poder da sugestão diminui a sensibilidade dos nervos, fazendo crescer a cefalalgia intensa que tanto martírio dava ao paciente, as lesões da infecção ganham terreno, os seus agentes específicos folgam e cantam vitória com a ausência dos medicamentos, e lá vem uma manhã em que, ao despertar encontra-se o curado da viseira a não poder abrir os olhos, ou completamente paralítico de um lado, ou incapaz de andar, enfim com uma das múltiplas manifestações graves da sífilis. (CORREIO DO BRASIL, 1903, p. 2.)

Para o articulista, Faustino seria um ótimo sugestionador que enganava a população com procedimentos curativos efêmeros e atrapalhava os processos de cura legitimados pelas instituições médicas. Na hipótese supracitada, as lesões não tardariam a se manifestarem de forma "irrevogavelmente irreparáveis", previa o articulista. Nesses termos, Faustino não poderia deixar de ser responsabilizado, mesmo não usando nenhuma "droga" ou produto medicinal. Para além dessa perspectiva, o autor ainda enfatiza outros "prejuízos" que Faustino poderia trazer como o abandono de trabalho para a consecução das curas, a "malandragem continuada, aumentando o gosto pelo sobrenatural e os instintos supersticiosos da população." (CORREIO DO BRASIL, 1903, p. 2.)

Relativo à modernização, esse discurso colocava Faustino enquanto "sugestionador" e "teósofo" como difusor - mesmo atendendo em um consultório - da malandragem e do 
abandono de trabalho, que antes de sua passagem por Salvador, estavam relacionados sobretudo aos sambas e aos batuques dos candomblés. Rotular os praticantes de tais artes como "sugestionador" e "teósofo" era um discurso da ordem do dia que buscava enquadrar aqueles que não se adequavam às normas do projeto de modernização idealizado à época que se fazia presente muito mais no campo das ideias dos grupos abastados do que materialmente.

\section{Considerações finais}

Nesse artigo, colocamos em evidências o cenário insalubre no qual diversos fatores contribuíram para a difusão de doenças na sociedade baiana do começo do século XX. Doenças que eram adquiridas e difundidas pela condição monoalimentar da dieta das pessoas que viviam em Salvador: beribéri; afecções estomacais; desnutrição e afins. Argumentamos que esses não foram os fatores exclusivos para a recorrência dos sofredores aos agentes de cura como Professor Faustino. Compunham, na realidade, um cenário no qual a inacessibilidade a médicos, a desestruturação de hospitais e a grande presença de feiticeiros, rezadeiras, benzedeiras e os mais diversos agentes de cura, não determinavam a constante busca de curas alternativas.

A perseguição a Faustino se justifica mais pela ânsia de inserir a sociedade nos caminhos do progresso preterido à época do que pela preocupação sistemática a prevenção de doenças infecciosas e pela preocupação com o estado de saúde da população. Esse era um discurso que enquadrava todos aqueles que figuravam como ameaça à ordem como sinônimos de atraso e incivilidade e precisavam, portanto, serem combatidos.

Alcunhado "discípulo de Mesmer" e de "sugestionador", Faustino curava a partir de princípios espíritas, mesmo que negasse tal prática como uma tática para se proteger de seus algozes. Mas ainda naquele tempo, o professor continuaria realizando suas "curas maravilhosas" por outras cidades da Bahia, o que teria aguda repercussão na imprensa e na Justiça.

REFERÊNCIAS BIBLIOGRÁFICAS 
BERTUCCl, Liane Maria. "Práticas de cura no período da gripe espanhola de São Paulo". Em: CHALHOUB, Sidney et al. (Org.) Artes e ofícios de curar no Brasil: capítulos de história social. Campinas: Editora Unicamp, 2003.

BRASIL. Superior Tribunal de Justiça. Processo Penal. Recurso Criminal. № 169, Salvador, Bahia, 23 de setembro de 1903. Salvador, 1904. Cx. 551. $80 f$

CARRETA, Jorge Augusto. "Oswaldo Cruz e a controvérsia da sorologia". História, Ciências, Saúde - Manguinhos, Rio de Janeiro. v. 18, n.3, jul.-set. 2011, p.677-700.

DAVID, Onildo Reis. O inimigo invisível: epidemia na Bahia no século XIX. Salvador: EDUFBA, 1996.

DIÁRIO da Bahia, Salvador. 26 jan. 1904. p. 3.

DIÁRIO de Bahia, Salvador. 3 jan. 1904. p. 3.

DIÁRIO de Notícias, Salvador. 10 de out. 1903. p. 2.

FERREIRA FILHO, Alberto Heráclito. "Desafricanizar as ruas: elites letradas, mulheres pobres e cultura popular em Salvador. (1890-1937)". Afro-Ásia, Salvador, 1998-1999.

FRANCO, Ariovaldo. O Século XIX - O apogeu dos padrões burgueses: a industria de alimentação. São Paulo: Editora SENAC, 2004.

GUIMARÃES, Maria Regina Cortim. "Chernoviz e os manuais de medicina popular no Império". História, Ciência e Saúde-Manguinhos, v. 12, n. 2, Rio de Janeiro, 2005.

MONTANARI, Massimo. A fome e a abundância: História da alimentação na Europa. São Paulo: EDUSC, 2003.

PADILHA, Estela Maura et all. "Perfil epidemiológico do beribéri notificado de 2006 a 2008 no Estado do Maranhão, Brasil". Cadernos de Saúde Pública, vol. 27, n. 3. Rio de Janeiro, 2011.

PATTO, Maria Helena Souza. "Estado, ciência e política na Primeira República: a desqualificação dos pobres". Estudos Avançados, v. 35, no 13, 1999.

PERIGO. Correio do Brasil. Salvador, 16 out. 1903. p. 2.

PIMENTA, Tânia Salgado. "Terapeutas populares e instituições médicas na primeira metade do século XIX". Em: CHALHOUB, Sidney et al. (Org.) Artes e ofícios de curar no Brasil: capítulos de história social. Campinas: Editora Unicamp, 2003.

PROFESSOR Faustino. Diário de Notícias. Salvador, 30 jul. 1903. p. 3. 
PROFESSOR Faustino. Diário de Notícias. Salvador, 8 ago 1903, p. 1.

PROFESSOR Faustino. Diário de Notícias. Salvador, 3 ago 1903. p. 5.

PROFESSOR Faustino. Diário de Notícias. Salvador, 4 ago 1903. p. 1.

PUBLICAÇÕES. Diário de Notícias. Salvador, 16 out. 1909. p. 7.

RELATÓRIO. O processo de cura do Professor Faustino. Diário de Notícias, 17 ago 1903. p. 1.

SANTOS, Mario Augusto dos. A República do Povo: sobrevivência e tensão - Salvador (18901930). Salvador: Edufba, 2001.

SOUZA, Christiane Maria Curz. A gripe espanhola na Bahia: saúde, política e medicina em tempos de epidemia. Rio de Janeiro: Fio Cruz; Salvador: Edufba, 2009.

WITTER, N. A.. “...os que não puderam se tratar em suas casas”. Em: Males e Epidemias: sofredores, governantes e curadores no sul do Brasil (Rio Grande do Sul, século XIX). $292 \mathrm{f}$. Tese (Doutorado em História Social) - Universidade Federal Fluminense, Niteroi. 2007.

XAVIER, Regina. "Dos males e suas curas: práticas médicas na campinas oitocentista". Em: CHALHOUB, Sidney et al. (Org.) Artes e ofícios de curar no Brasil: capítulos de história social. Campinas: Editora Unicamp, 2003. 